\title{
EFFECT OF SKILL ACQUISITION AMONG POULTRY FARMERS IN DELTA STATE
}

\author{
ONORIODE, OMORHO HUMPHREY \\ Department of Business Administration and Management \\ Delta State Polytechnic, Ozoro \\ EMAIL: onoriodehumphrey@yahoo.co.uk
}

AND

AGBELE GEORGE Ph.D

EMAIL: georgeashams@gmail.com

\begin{abstract}
The study aimed at determining the effect of skill acquisition on poultry farming industry in Delta State. We have a population of 102 from the selected 7 poultry farms in the area under study which as well comprises employers, employees and casual workers of the selected farms. Hypotheses were tested with correlation coefficient $(r)$ tool. Sample size was determined with Taro Yamene formula; hence, 83 sample size was obtained. The instrument used for data collection was both structured and unstructured questionnaire. Unstructured instrument was employed for the sake of those that could not read, hence, face-to-face method of discussion was ideal. Pearson Product Moment (PPM) correlation coefficient ( $r$ ) was equally adopted for data analysis. In line with the analysis, it was observed that strong positive relationship exist between experience of poultry farmers and farming industry, While indifferent (negative) correlation was revealed between knowledge and farming industry because a higher value was obtained for the critical value than the calculated value (0.75 > 0.52). The study concluded that experience positively affect poultry farming industry. The study recommended that farmers should employ or hire experienced poultry farmers for impartation of more experience through mentoring and tutoring. They are also advised to seek counsel from professionals for knowledge and skill acquisition to enhance sustainability in poultry farming industry, exposing them to conferences is equally suggested.
\end{abstract}

Keywords: Skill Acquisition, Poultry, Industries, Farming 


\section{Introduction}

Because of the benefit that is attached to poultry farming industry locally and internationally, there is a big concern for the industry. Over the past three decades, the poultry sector has been growing at more than 5 percent per annum (compared to 3 percent for pig and 1.5 percent for brovine) and its share in world meat production increase from 15 percent three decades ago to 30 percent currently (FAO, 2006a). Sequel to that, there is need for sustainability and improvement through skill acquisition. Nwachukwu (2004) opines that training is the organizational effort which is been aimed at helping an employee to acquire basic skills required for the efficient execution of the function for which he/she is hired. Improvement in skills encourages employee turnover and retention in work place. An employee that is given the necessary skills to do better in his work place is sometimes being encouraged to put in his/her best to complement the efforts of the organization. He/she is equally challenged to improve in their performances.

Experience has taught us that poultry farming industry would have taken another dimension in our business environment if the required training and skill is provided for the industry. Vemic (2017) notes that continuous employee training and development has a significant role in the development of individual and organizational performance and does not imply only obtaining new knowledge, skill and abilities, but also the possibility to promote entrepreneurship, introduce employees to changes, encourages the change of their attitude, introduce the employee to important business decisions and involve them actively in the process of decision making. Continuous skill acquisition method in poultry farming industry will expose them to modern technology in the field of poultry farming that will equally guarantee their stay in the market.

\section{Conceptual Framework}

Skill Acquisition: Skill refers to manual work which can be learned or acquired such as a carpenter, an electrician, computer operator and so on. Having enough experience, knowledge and ability to perform well on any assignment can also be referred to as being skilful. Acquisition is the process by which you gain knowledge (Know-how), or learn a skill. When there is acquisition of new knowledge within the organization, the capacity of employees increases and they become able to transform it and generate the new one (Chen \& Huang, 2009). When this happens, there is every tendency to exploit every available new opportunity as well which automatically give room for new innovations that result to increase in productivity. As far as the sustainability of poultry farming industry is concerned, the role of skill acquisition can never be overestimated. The need for poultry farmers to get themselves acquainted and informed with the current skills, ideas, knowledge of the enterprise must not be compromised.

Furthermore, acquired skill or knowledge enables entrepreneur to manage his/her enterprise very well in the area of marketing function, administrative function, external relation function, purchasing function, financial function (Onwukwe, 2009). It is the knowledge or skill that an individual acquired that enables him/her to function, every individual can only act based on what they know. Job performance is mainly determined by how well an employee is able to meet the expectation of organization, and how well the employees are able to show high level of professionalism in performing their tasks (Ida, 2017). Exhibiting professionalism is dependent on the skill, knowledge and level of experience acquired and every serious minded poultry farmers must not stay away from this fact. 
Experience of a Farmer and Poultry Farming: Work experience is critical and fundamental to the success of any organization. Experience to a very large extent determines how far an organization could go in terms of sustainability and surviving any competitive environment. Customer's reaction to products and services is also dependent on work experience. ARDA (2012) states that work experience of employee has a major effect on how the customer views the quality of goods and services. Deloitt (2016) opines that establishing the right experience has been a fundamental question that an organization must ask i.e. how to find the right employee in operation and how would that help deliver great result? An engineer cannot be found in the school of business studies, while a marketer cannot be seen in engineering school.

The quality of an organization workforce determine the overall performance of such organization; performance in the area of productivity, sales, quality of service delivery and the overall management of the organization can be traced to the quality of an organization workforce (Ida, 2016). Poultry farming industry must take the issue of experience very seriously in terms of technology and current issues that boder on poultry farming industry to stand the test of time. The quality of employee is only been accessed based on their input in the organization, and this can as well be determined or ascertained based on the employee's experience or know-how.

Knowledge and Poultry Farming Industry: According to Oxford Advanced Learner's Dictionary, Knowledge is information, understanding and skill that you gain through education or experience. Knowledge could also be seen as scientific or technological expertise, experience, operational know-how, insight about an industry and business processes. The explicit knowledge (that can be shared with others) that we are concerned about might not only be through formal method of learning. The knowledge that poultry farmers need that will shoot the industry to the next level of operation might not necessarily be going to higher institution. This could be acquired through informal means - friendly, approach. So many people today have performed excellently in their areas of endeavors through the knowledge, experience and understanding received from their parents, friends and even siblings. Training and acquiring knowledge that will propel any poultry farmer to higher dimension is based on individual readiness to learn and acquire. Poultry farmer has attended conferences yet without making any meaningful progress in their field of operation. The essence of this study is to encourage poultry on the need for them to acquire and retain knowledge on the current information and operational system needed for them to stand the competitive market. Is a more waste of time or any farmer to think of standing the test of time without being equipped in their field of operation. Technological advancement can only be imparted through knowledge acquired. What you know is a determining factor whether you will survive any market situation you find yourself or not. Poultry farming industry is area of great concerned that must be given adequate attention for economic development and productivity.

\section{Materials and Methods}

The population comprised 7 poultry farms with a total population of 102 workers (employers, employees and the casual workers) which were selected across the study area. We have sample size of 83 which was ascertained through Taro Yemene formula. We adopted both primary and secondary sources of data. The instruments used for data collection was both structured and unstructured questionnaire. We employed the unstructured method (face-toface) because of the uneducated among the workers. It was also a survey research design. 2 
hypotheses were tested using correlation coefficient (r) measurement tool. The collected data was equally subjected to Pearson Product Moment (PPM) correlation coefficient statistical tool for analysis:

$$
\mathrm{r}=\frac{\mathrm{n}\left(\sum x y-\left(\sum x\right)\left(\sum y\right)\right.}{\sqrt{n\left(\sum X^{2}-\sum X\right)^{2}\left(n\left(\sum Y^{2}-\sum Y\right)^{2}\right.}}
$$

Sample Size: Taro Yemen formula as adopted for determining sample size

$$
\begin{aligned}
& S=\frac{N}{1+N \alpha^{2}} \\
& S=\frac{102}{1+116(0.05)^{2}} \\
& S=\frac{102}{1+(106 \times 0.05 \times 0.05)} \\
& S=\frac{102}{1+(106 \times 0.0025)} \\
& S=\frac{106}{1+0.27} \\
& S=\frac{106}{1.27} \quad \therefore \text { Sample Size }
\end{aligned}
$$

\section{Testing Hypotheses}

\section{Testing of Hypothesis I}

Correlation coefficient (r) was employed in testing hypothesis I and II

$\mathrm{H}_{0}$ : $\quad$ Experience of farmers has no significant positive effect on poultry farming in Delta state. 
Table 1.1: Result of the Respondents response for skill acquisition and experience of farmer in poultry farms in Delta State.

\begin{tabular}{|l|l|l|}
\hline Enterprise (Variables) & Skill Acquisition $(\mathbf{X})$ & Experience of Farmer $(\mathbf{Y})$ \\
\hline Poultry Farm & 8 & 5 \\
\hline Poultry Farm & 4 & 5 \\
\hline Poultry Farm & 14 & 11 \\
\hline Poultry Farm & 3 & 3 \\
\hline Poultry Farm & 5 & 5 \\
\hline Poultry Farm & 9 & 4 \\
\hline Poultry Farm & 17 & 14 \\
\hline Total & 62 & 47 \\
\hline
\end{tabular}

Source: Researchers' Field Survey 2021

The skill acquisition is represented by $\mathrm{X}$ variable, while the experience of farmer is represented by $\mathrm{Y}$ variable. The coefficient correlation is represented by ( $r$ ).

Where: $\mathrm{X}=$ Independent Variable

$$
\mathrm{Y}=\text { Dependent Variable }
$$

Table 1.1 above shows the correlation between skill acquisition and experience of farmer in poultry farm industry. SA represent Skill Acquisition, while EF represents Experience of Farmer. Responses were in 7 point Liker Scale: Very Good (VG), Good (G), Fairly Good (FG), Indifferent (I), Fairly Bad (FB), Bad (B) \& Vey Bad (VB) which were also explained in percentage. Results of the variables are shown below:

$$
\begin{aligned}
& \mathrm{SA}=8(9.6 \%)>\mathrm{EF}=5(6.0 \%) \\
& \mathrm{SA}=4(4.8 \%)<\mathrm{EF}=5(6.0 \%) \\
& \mathrm{SA}=14(16.8 \%)>\mathrm{EF}=14(13.2 \%) \\
& \mathrm{SA}=5(6.0 \%)>\mathrm{EF}=3(3.6 \%) \\
& \mathrm{SA}=5(6.0 \%) \geq \mathrm{EF}=5(6.0 \%) \\
& \mathrm{SA}=9(10.8 \%)>\mathrm{EF}=4(4.8 \%) \\
& \mathrm{SA}=17(20.4 \%)>\mathrm{EF}=14(16.8 \%)
\end{aligned}
$$

$\therefore$ Thus, the total scores of the respondents at Skill Acquisition (SA) and Experience of Farmers $(\mathrm{EF})$ in poultry farm were indicated as: $\{\mathrm{SA}=62(74.4 \%)\}>\{\mathrm{EF}=47(56.4 \%)\}$. 
Table 1.2: Determination of Correlation Coefficient ( $r$ )

\begin{tabular}{|c|c|c|c|c|c|c|c|c|c|}
\hline $\mathbf{X}$ & $\mathbf{Y}$ & $\mathbf{X}^{2}$ & $\mathbf{Y}^{2}$ & $\mathbf{X Y}$ & SL (r) & DF & Critical Value & Cal. Value & Decision Rule \\
\hline 8 & 5 & 64 & 25 & 40 & \multirow{8}{*}{5} & \multirow{8}{*}{$5 \%$} & \multirow{8}{*}{0.75} & \multirow{8}{*}{0.91} & \multirow{8}{*}{$\mathrm{H}_{1}$ : Accepted } \\
\hline 4 & 5 & 16 & 25 & 20 & & & & & \\
\hline 14 & 11 & 196 & 121 & 154 & & & & & \\
\hline & & & & & & & & & \\
\hline 5 & 3 & 25 & 9 & 15 & & & & & \\
\hline 5 & 5 & 25 & 25 & 25 & & & & & \\
\hline 9 & 4 & 81 & 14 & 36 & & & & & \\
\hline 17 & 14 & 289 & 196 & 238 & & & & & \\
\hline 62 & 47 & 698 & 417 & 528 & & & & & \\
\hline
\end{tabular}

Calculating for $r$

$$
\begin{aligned}
& \mathrm{r}=\frac{\mathrm{n}\left(\sum x y-\left(\sum x\right)\left(\sum y\right)\right.}{\sqrt{n\left(\sum X^{2}-\sum X\right)^{2}\left(n\left(\sum Y^{2}-\sum Y\right)^{2}\right.}} \\
& =\frac{7(528-(62)(47)}{\sqrt{\left(7(698-62)^{2}\right)\left(7(417-47)^{2}\right)}} \\
& =\quad \frac{(3696)-(2914)}{\sqrt{(4872)-3844)(2919-2209)}} \\
& =\frac{782}{\sqrt{(1028)(710)}} \\
& = \\
& =\frac{782}{\sqrt{729880}}
\end{aligned}
$$




\begin{tabular}{ll}
$=$ & 782 \\
\cline { 2 - 2 } & 854 \\
& 0.91
\end{tabular}

Decision Rule

$\mathrm{Df}=\mathrm{N}-2$

Df $=7-2=5$

$\mathrm{Df}=5$

$\mathrm{r}=$ Critical Value at $5 \%=0.75$

Therefore, calculated value of $0.91>$ critical value of 0.75 . By the decision rule, the $\mathrm{H}_{0}$ is discarded while $\mathrm{H}_{1}$ is retained because a significant correlation was observed.

\section{Testing Hypothesis II}

$\mathrm{H}_{0}$ : Knowledge of poultry farmers has no significant positive impact on poultry farming industry in Delta state.

Table 1.3: Result summary for Skill Acquisition and Knowledge of Farmers in Poultry Farming Industry in Delta State.

\begin{tabular}{|l|l|l|l|l|l|l|l|l|l|l|l|l|l|l|}
\hline Enterprises (Variables) & \multicolumn{4}{l|}{ Skill Acquisition (X) } & \multicolumn{4}{|l|}{ Knowledge of Farmers (Y) } \\
\hline & VG & G & FG & I & FB & B & VB & VG & G & FG & I & FB & B & VB \\
\hline Poultry Farm & 2 & 1 & 3 & 1 & 1 & 1 & 1 & 2 & 1 & 2 & 2 & 1 & 2 & 0 \\
\hline Poultry Farm & 2 & 2 & 2 & 1 & 0 & 2 & 1 & 2 & 1 & 1 & 2 & 1 & 3 & 0 \\
\hline Poultry Farm & 1 & 3 & 1 & 2 & 3 & 0 & 0 & 2 & 2 & 2 & 1 & 3 & 2 & 2 \\
\hline Poultry Farm & 2 & 3 & 2 & 1 & 1 & 1 & 1 & 1 & 1 & 0 & 1 & 1 & 0 & 1 \\
\hline Poultry Farm & 2 & 2 & 2 & 1 & 1 & 2 & 2 & 1 & 2 & 2 & 1 & 1 & 1 & 2 \\
\hline Poultry Farm & 2 & 1 & 1 & 3 & 2 & 2 & 2 & 1 & 3 & 1 & 1 & 2 & 1 & 2 \\
\hline Total & 11 & 12 & 11 & 9 & 8 & 8 & 7 & 9 & 10 & 8 & 8 & 9 & 9 & 7 \\
\hline Sourcencly
\end{tabular}

Sources: Researchers' Field Survey 2021

The skill acquisition is represented by $\mathrm{X}$ variable, while the knowledge of farmer is represented by $\mathrm{Y}$ variable. The coefficient correlation is represented by (r).

Where: $\mathrm{X}=$ Independent Variable

$\mathrm{Y}=$ Dependent Variable 
The information in table 1.3 above shows correlation between skill acquisition and knowledge of farmer in poultry farm industry. SA represents Skill Acquisition, while KF represents Knowledge of Farmer. The items were responded to in 7 point Liker Scale: Very Good (VG), Good (G), Fairly Good (FG), Indifferent (I), Fairly Bad (FB), Bad (B) \& Vey $\mathrm{Bad}(\mathrm{VB})$ and were equally explained in percentage. Results of the variables are shown below:

$$
\begin{aligned}
& \mathrm{SA}=11(13.2 \%)>\mathrm{KF}=9(10.8 \%) \\
& \mathrm{SA}=12(14.4 \%)<\mathrm{KF}=10(12.0 \%) \\
& \mathrm{SA}=11(13.2 \%)>\mathrm{KF}=8(9.8 \%) \\
& \mathrm{SA}=9(10.8 \%)>\mathrm{KF}=8(9.8 \%) \\
& \mathrm{SA}=8(9.6 \%) \geq \mathrm{KF}=9(10.8 \%) \\
& \mathrm{SA}=8(9.6 \%)>\mathrm{KF}=9(10.8 \%) \\
& \mathrm{SA}=7(8.4 \%)>\mathrm{KF}=7(8.4 \%)
\end{aligned}
$$

\begin{tabular}{|c|c|c|c|c|c|c|c|c|c|}
\hline $\mathbf{X}$ & $\mathbf{Y}$ & $\mathbf{X}^{2}$ & $\mathbf{Y}^{2}$ & $\mathbf{X Y}$ & SL (r) & DF & Critical Value & Cal. Value & Decision Rule \\
\hline 11 & 9 & 121 & 81 & 99 & \multirow{8}{*}{5} & \multirow{9}{*}{$5 \%$} & \multirow{9}{*}{0.75} & \multirow{9}{*}{0.52} & \multirow{9}{*}{$\mathrm{H}_{0}$ : Retained } \\
\hline 12 & 10 & 144 & 120 & 120 & & & & & \\
\hline 11 & 8 & 121 & 64 & 88 & & & & & \\
\hline & & & & & & & & & \\
\hline 9 & 8 & 81 & 64 & 72 & & & & & \\
\hline 8 & 9 & 64 & 81 & 72 & & & & & \\
\hline 8 & 9 & 64 & 81 & 72 & & & & & \\
\hline 7 & 7 & 49 & 49 & 49 & & & & & \\
\hline 66 & 59 & 644 & 540 & 572 & & & & & \\
\hline
\end{tabular}

$\therefore$ Thus, the total scores of the respondents at Skill Acquisition (SA) and Knowledge of Farmers $(\mathrm{KF})$ in poultry farm were indicated as: $\{\mathrm{SA}=66(79.2 \%)\}>\{\mathrm{KF}=59(72.4 \%)\}$.

Table 1.4: Determination of Correlation Coefficient (r) 
Calculating for $r$

$$
\begin{aligned}
& \mathrm{r}=\quad \mathrm{n}\left(\sum x y-\left(\sum x\right)\left(\sum y\right)\right. \\
& \overline{\sqrt{n}\left(\sum X^{2}-\sum X\right)^{2}\left(n\left(\sum Y^{2}-\sum Y\right)^{2}\right.} \\
& 7(572)-(66)(59) \\
& = \\
& \sqrt{\left(7(644-66)^{2}\right)}\left(7(540-59)^{2}\right) \\
& =\quad(4004)-(3894) \\
& \sqrt{(4508)-4356)(3780-3481)} \\
& \begin{array}{ll}
= & 10
\end{array} \\
& \sqrt{(152)(299)} \\
& =\quad 110 \\
& \sqrt{45448} \\
& =\quad 110 \\
& 2134 \\
& =0.52
\end{aligned}
$$

Decision Rule

$\mathrm{Df}=\mathrm{N}-2$

$\mathrm{Df}=7-2=5$

$\mathrm{Df}=5$

$\mathrm{r}=$ Critical Value at $5 \%=0.75$

By the application of correlation coefficient test, Null hypothesis is accepted while the alternative hypothesis is rejected because the critical value $0.75>0.52$ calculated value at $5 \%$ (0.05) significant level. 


\section{Discussion of Findings}

The growth, development and continuity of poultry farming is firmly anchored on experience of farmers; this is because there is strong positive correlation between the dependent and independent variables based on the analysis $(0.91>0.75)$. In other words, poultry farming industry has been sustained because of the experience and intelligence of the farmer on that regard. But reversed was the result for knowledge of farmers and poultry farming industry in the area under study. We observed indifferent relationship between variable $\mathrm{X}$ and $\mathrm{Y}$. It suggests that over the years poultry farmers do not have access to the knowledge that would have revamped the industry. It further suggests that the low productivity and continuous close down, uncontrollable crisis and challenges of poultry farming industry in the area may also be connected or linked to lack of knowledge.

Conclusion and Recommendations: In line with the discussion of findings, the study concludes that the experience of farmer in Delta state has a positive significant effect on poultry farming industry, while knowledge of farmers has insignificant impact on poultry farming because negative relationship was observed between variable $\mathrm{X}$ and $\mathrm{Y}$. Sequel to that, the study recommended that community leaders and government should encourage the experience and intelligence of these farmers at the grassroot by exposing them to mechanized farming to improve the poultry farming industry. Again, farmers should employ or hire experienced poultry farmers on contract basis who will occasionally or periodically spend time with them for more experience, impartation and proper tutoring and mentoring until they are fully established in that field. Furthermore, they should attach themselves to old poultry farmers to get the foreknowledge of the business and the knowledge of keeping poultry farm. This will enable them to mature in handling some challenging situations when it arises. They are advised to seek advice from professionals in that field. Exposing them to conferences in poultry farming is also suggested for efficient performance. 


\section{References}

Chen, C. J \& Huang J. W. (2009). Strategic Human Resources Practice and Innovation Performance: The mediating Role of Knowledge Manangement Capacity. Journal of Business Research. Vol. 62, No 1, PP. $104-114$.

Deloitt, (2016). Global Human Capital Tremals 2016: The New Organization: Different by Design. Deloitt University Press

Ida, W. N. (2017). Effect of Employee's Work Experience on Performance within Hotel Industry: A case of Amber Hotel Kenya.

Oxford Advanced Learner's Dictionary: Special Price Edition.

Nwachukwu, C. (2004). Management: Theory and Practice: Africana-Fep-Publisher Limited, Anambra State, Nigeria. 